\title{
The Assessment of the Knowledge About Adult Vaccine, And Vaccination Coverage in Adults Aged 18 and Older In Turkey
}

\author{
Bekir Uragan Ineli \\ Department of Family Medicine, Akdeniz University Hospital, Akdeniz University, Faculty of \\ Medicine, Antalya, Turkey \\ Email. bekirineli@yahoo.com \\ Melahat Akdeniz \\ Department of Family Medicine, Akdeniz University Hospital, Akdeniz University, Faculty of \\ Medicine, Antalya, Turkey \\ Email: melahatakdeniz@gmail.com \\ Ethem Kavukcu (Corresponding author) \\ Department of Sports Medicine, Akdeniz University Hospital, Akdeniz University, Faculty of \\ Medicine, Antalya, Turkey \\ Email:ethemkavukcu@gmail.com
}

These authors contributed equally to this work. The research is financed by the authors

\begin{abstract}
Objectives: Vaccinations are accepted as being one of the most effective methods for protecting health and preventing illness. The purpose of this study is to assess the vaccination coverage of the adults aged 18 and older, who have made an application to the Family Medicine polyclinics in Antalya, Turkey, as well as their knowledge and desire to obtain knowledge concerning vaccinations.
\end{abstract}

Materials and Methods: This cross-sectional and descriptive study has been conducted by way of faceto-face questioning. The statistical analyses have been performed using SPSS ver. 22.0. The sample size has been calculated as 400, with the "OpenEpi.Version 3 Open Source Calculator". The Chi-Square, Kruksal-Wallis test and Spearman correlation analysis were used.

Results: A total of 445 people participated in the study. Vaccination coverage for the participants was 10.8 for influenza on a regularly every year, $24,3 \%$ for tetanus and diphtheria (Td) on regularly every ten years, $30.3 \%$ for hepatitis B, $6.0 \%$ for pneumococcal vaccine. The most frequent reason cited for not getting vaccinations was a lack of knowledge. About $65 \%$ of the participants stated that they wished to be informed about adult vaccinations by their family practitioners.

Conclusion: Vaccinations are the cornerstone of being protected against infectious diseases. In our region adults do not have sufficient information concerning the vaccinations which are necessary during adulthood, and their vaccination coverage are lower than the desired targets.

Key words: Vaccination coverage, adult immunization, knowledge.

DOI: $10.7176 / \mathrm{JSTR} / 5-5-03$

\section{Introduction}

The discovery of vaccines is a turning point in the fight against infectious diseases. The prevalence of numerous infectious diseases, which were at the top of the list of fatal diseases, is quickly reduced with the start of vaccinations [1]. While being performed with success during the childhood years, vaccinations which are of vital importance for protecting the health of the community, are far from the desired level during adulthood. Vaccinations are accepted as one of the most effective methods for protecting health and preventing illness, but in many countries around the world, including Turkey, the coverage of adult vaccinations are not at the desired level [2-4]. 
Today, the majority of the vaccine preventable disease appears in adults [4]. Adults are sensitive to certain infectious diseases which can be prevented through vaccinations. This is due to fact certain people were not vaccinated during childhood, and some vaccines not provide life-long immunity. Moreover, the fact that certain illnesses such as measles, varicella and hepatitis, which are less serious during childhood, may be more severe in adulthood and the co-morbid status of the aged. Adults can be affected more than the complications of infectious diseases [1,5].

Infectious diseases not only affect the people who have been infected, but can also affect the whole family, the individuals working in the same environment and the community, both directly and indirectly. Vaccinations during adulthood do not only provide protection from infectious diseases, but at the same time, they help to control of co-morbid illnesses easier, and to prevent the transmission of infections to other people who are at risk, and in particular to small children [1,3]. Therefore, it is recommended that vaccinations are implemented throughout the whole life of individuals, in order to prevent diseases which can be prevented through vaccinations $[3,5,6]$.

The Advisory Committee on Immunization Practices (ACIP) of the USA recommends vaccinations against 13 infectious diseases - based on different risk factors and age - including influenza, diphtheria, tetanus, pertussis, varicella, human papillomavirus, measles, mumps, rubella, pneumococcal diseases, meningococcal diseases, hepatitis A and B, haemophilus and herpes zoster. In Turkey, the Ministry of Health recommends the vaccines against influenza, tetanus, hepatitis B, pneumococcal diseases and meningococcal diseases based on different risk factors and age. The other vaccines are not within the scope of reimbursement [7]. However, adult vaccinations have been a subject which attention has been paid to in recent years in Turkey. The Adult Immunisation Guide Working Group, led by the Association of Clinical Microbiology for Infectious Diseases established the Adult Immunisation Guide in 2016. The recommendations for adult vaccinations contained in this guide, are similar to those of the ACIP [7].

Studies for determining the adult vaccination coverage have been conducted in the USA, Canada and numerous other countries [2,3,7-11]. There is no countrywide study in Turkey related to adult vaccination coverage. Studies have been small scale and included only at certain vaccines [12-16]. The aim of our study is to assess vaccination status of the adults aged 18 and older in our region, with the recommended vaccines during adulthood, and their knowledge and desire to acquire information on adult vaccinations.

\section{Materials and methods}

The vaccination status, level of knowledge about adult vaccinations and the reasons for not getting vaccinated were researched with a face-to-face survey conducted with adults over the age of 18, who had applied to the two outpatient clinics of the Akdeniz University, Faculty of Medicine, Department of Family Medicine. The size of the sample for this study which we designed as cross-sectional and descriptive was calculated as 400 with the "OpenEpi.Version 3. open source calculator", with the reliability level taken as $99 \%$, the frequency percentage as $50 \%$, the confidence interval as $5 \%$ and the sample error as 0.05 .

A 25 -question questionnaire was implemented on 445 volunteers, who had agreed to take part in the study and given their consent between the months of April - July 2015.

In Turkey, although the childhood immunization records are kept scrupulously, records for adult immunizations are not kept properly. For this reason, immunization status of the participants has been learned from themselves during the one-to-one interview.

The statistical analyses were performed using SPSS ver. 22.0. Mean and standard deviation was used in the descriptive analyses, while the Chi-Square and Kruskal-Wallis tests and spearman correlation analysis were used for the analysis of categorical data. The $\mathrm{P}<0.05$ value was deemed to be significant. Ethical approval was obtained for the study from the Akdeniz University Clinical Research Ethics Committee (date and number: 29.04.2015/205).

\section{Results}

A total of 445 individuals - 318 females $(71.5 \%)$ and 127 males (28.5\%) - participated in the study. The mean age of the participants was $38 \pm 2$ years. About fifty-two percent of participants declared that they had no knowledge about adult vaccinations. The most frequent reasons for not having any knowledge were "not being informed by any source" $(84.1 \%)$ and "not think to be necessary to have knowledge" $(10.6 \%)$. Table 1 shows that percentage of aware among participants who declared they had knowledge concerning vaccinations, based on different vaccines and vaccination coverage of participants.

Approximately $30 \%$ participants stated that they did not get any vaccines during adulthood. From those participants who stated that they had got any vaccine, $52.3 \%$ stated that they had got at least one dose of tetanus vaccine (Td), 31.9\% at least one dose of influenza vaccine. Vaccination coverage of other vaccines for all participants throughout the whole period of adulthood are shown in Table 1. The

18 | P a g e 
vaccination coverage for people with chronic diseases was not at the desired level. Table 2 shows the rates at which patients with chronic diseases had vaccinations.

Table 1. Percentage of aware among participants who declared they had knowledge concerning vaccinations, based on different vaccines and vaccination coverage of participants

\begin{tabular}{|l|c|c|}
\hline \multicolumn{1}{|c|}{ Vaccines } & $\begin{array}{c}\text { Participant } \\
\text { familiar with } \\
\text { vaccination (\%) }\end{array}$ & $\begin{array}{c}\text { Vaccination coverage of } \\
\text { for participants aged 18 } \\
\text { years and older (\%)* }\end{array}$ \\
\hline Influenza & 75.1 & 52.4 \\
\hline Tetanus, diphtheria (dT) & 69.4 & 31.9 \\
\hline Hepatitis B & 55.3 & 30.3 \\
\hline Hepatitis A & 38.9 & 9.0 \\
\hline Human Papillomavirus (HPV) & 33.5 & 5.4 \\
\hline Pneumococcal & 30.1 & 2.2 \\
\hline Measles, mumps, rubella (MMR) & 28.8 & 1.8 \\
\hline Varicella & 24.3 & 1.3 \\
\hline Meningococcal & 19.8 & 0.9 \\
\hline Zoster & 13.7 & 0.9 \\
\hline Haemophilus influenzae type b (Hib) & 11.2 & 0.2 \\
\hline *There is no legally compulsory vaccination program for healthy adults in Turkey. \\
\hline
\end{tabular}

Table 2. Vaccination rates of participants with chronic disease

\begin{tabular}{|c|c|c|c|c|c|c|c|c|c|}
\hline DISEASES & \begin{tabular}{|c|} 
DM \\
$(\mathrm{n}=40)$
\end{tabular} & $\begin{array}{c}\text { Heart } \\
\text { Disease } \\
(n=16)\end{array}$ & $\begin{array}{c}\text { Lung } \\
\text { Disease } \\
(\mathbf{n}=13)\end{array}$ & $\begin{array}{c}\text { Liver } \\
\text { Disease } \\
(\mathrm{n}=7)\end{array}$ & $\begin{array}{c}\text { Kidney } \\
\text { Disease } \\
(\mathrm{n}=\mathbf{3})\end{array}$ & \begin{tabular}{|c|} 
Organ \\
Transpl \\
ant \\
$(\mathbf{n}=1)$ \\
\end{tabular} & $\begin{array}{l}\text { Immune } \\
\text { deficiency } \\
(n=2)\end{array}$ & $\underset{(\mathbf{n}=1)}{\mathrm{HIV}}$ & $\begin{array}{c}\text { Blood } \\
\text { Diseases } \\
(\mathbf{n}=1)\end{array}$ \\
\hline VACCINES & $(\%)$ & $(\%)$ & $(\%)$ & $(\%)$ & $(\%)$ & $(\%)$ & $(\%)$ & $(\%)$ & $(\%)$ \\
\hline $\begin{array}{l}\text { Influenza } \\
\text { vaccine }\end{array}$ & 42.5 & 43.8 & 30.8 & 42.9 & 33.3 & 0 & 0 & 0 & 0 \\
\hline $\begin{array}{l}\text { Tetanus- } \\
\text { diphtheria } \\
\text { vaccine } / \mathrm{Td} \text { ) }\end{array}$ & 40.0 & 35 & 53.8 & 14.3 & 33.3 & 100 & 50.0 & 100 & 100 \\
\hline $\begin{array}{l}\text { Pneumococcal } \\
\text { vaccine }\end{array}$ & 7.5 & 12.5 & 0 & 0 & 0 & 0 & 0 & 0 & 0 \\
\hline $\begin{array}{l}\text { Meningococcal } \\
\text { vaccine }\end{array}$ & 2.5 & 0 & 0 & 0 & 0 & 0 & 0 & 0 & 0 \\
\hline HAV vaccine & 0 & 0 & 15.4 & 0 & 33.3 & 0 & 0 & 100 & 0 \\
\hline HBV vaccine & 12.5 & 25.0 & 23.1 & 14.3 & 33.3 & 0 & 0 & 100 & 0 \\
\hline Hib vaccine & 0 & 0 & 0 & 0 & 0 & 0 & 0 & 0 & 0 \\
\hline
\end{tabular}

In response to the question of "would you have get the vaccination if you had knowledge about vaccines", $27.7 \%$ of participants in the 19-26 age group stated that they may have get the HPV vaccination. The other details concerning attitudes in respect of influenza, pneumococcal, tetanus and HPV vaccinations are given in Table 3.

The most frequently stated reasons for not get vaccinations are "insufficient information" and "no particular reason" (34.4\% and $27.2 \%$ respectively). The rates related to the reasons why adults did not get vaccinations are given in Table 4.

In respect of the source from which they wished to obtain information, about percent sixty-five of the participants pointed the family practitioner, $32.6 \%$ pointed public announcement spots, $21.1 \%$ pointed printed materials and $18.0 \%$ pointed the vaccination campaigns. 
Table 3. The attitudes of the participants concerning certain vaccinations

\begin{tabular}{|c|c|c|c|}
\hline VACCINES & ATTITUDE & $\underset{(n)}{\text { Number }}$ & $\begin{array}{c}\text { Percentage } \\
(\%)\end{array}$ \\
\hline \multirow{4}{*}{$\begin{array}{l}\text { Influenza vaccine } \\
\text { (Participants from every age } \\
\text { group and every year) }\end{array}$} & Regularly every year & 48 & 10,8 \\
\hline & Not regularly & 304 & 68,3 \\
\hline & May do if he/she had knowledge & 93 & 20,9 \\
\hline & TOTAL & 445 & 100,0 \\
\hline \multirow{4}{*}{$\begin{array}{l}\text { Pneumococcus vaccine } \\
\text { (participants who are under } \\
\text { risk* and over the age of } 65 \text {, } \\
\text { every } 5 \text { years) }\end{array}$} & Every 5 years & 6 & 6,0 \\
\hline & Not regularly & 75 & 73,5 \\
\hline & May do if he/she had knowledge & 21 & 20,5 \\
\hline & TOTAL & 102 & 100,0 \\
\hline \multirow{4}{*}{$\begin{array}{l}\text { Tetanus vaccine (participants } \\
\text { from every age group, booster } \\
\text { every } 10 \text { years) }\end{array}$} & Booster dose every 10 years & 108 & 24,3 \\
\hline & Not regularly & 263 & 59,1 \\
\hline & May do if he/she had knowledge & 74 & 16,6 \\
\hline & TOTAL & 445 & 100,0 \\
\hline \multirow{5}{*}{$\begin{array}{l}\text { HPV vaccine (Participants } \\
\text { between the ages of 19-26) }\end{array}$} & Had it as three doses & 2 & 2,5 \\
\hline & Not had it & 58 & 71,6 \\
\hline & May do if he/she had knowledge & 20 & 24,7 \\
\hline & No response & 1 & 1,2 \\
\hline & TOTAL & 81 & 100,0 \\
\hline
\end{tabular}

Table 4. The reasons why the participants do not get vaccinations

\begin{tabular}{|l|c|}
\hline Reason for not having vaccinations & Rate (\%) \\
\hline Insufficient Information about vaccines & 34.4 \\
\hline No Particular Reason & 27.2 \\
\hline Fear of the Side Effects & 9.0 \\
\hline Believing the Vaccines not to be Protective & 8.8 \\
\hline Not Being within the scope of Reimbursement & 5.8 \\
\hline High Costs & 4.7 \\
\hline Fear of Injections & 2.5 \\
\hline Presence of Allergies & 1.1 \\
\hline Other & 8.1 \\
\hline
\end{tabular}

\section{Analysis of the Categorical Data}

There was a significant difference between health workers and other occupational groups in terms of having influenza, tetanus, HAV and HBV vaccinations $(\mathrm{p}<0.05)$. Participants who are healthcare workers have had these vaccinations at higher rates. However, there is no significant difference between health workers and other occupational groups in respect of having other vaccinations $(p>0.05)$.

Although the rate of those having the influenza vaccination among those with chronic diseases was higher (39.7\% as against $28.8 \%$ respectively), the difference was statistically significant $(\mathrm{p}<0.05)$. The pneumococcal vaccination was also more prevalent among those with chronic diseases (4.8\% as against $1.3 \%$ respectively).

There was a significant difference between the male and female participants in terms of their attitudes to the influenza vaccine, with regular annual influenza vaccinations being more prevalent amongst males than amongst females $(16.5 \%$ as against $8.5 \%$ respectively) $(\mathrm{p}<0.05)$.

There was a significant difference between the male and female participants in terms of receiving the pneumococcal vaccination $(\mathrm{p}<0.05)$. Pneumococcal vaccination rate is higher in males than in females (6.3\% as against $2.2 \%$ respectively). There is no difference between those with chronic illnesses and those without, in respect of receiving pneumococcal vaccinations $(p>0.05)$. 


\section{Discussion}

Adult vaccination programmes display significant differences in various countries throughout the world. While there are up to 16 vaccines in the adult vaccination programmes in certain countries, this number is lower in others. In Turkey, reimbursement is made to certain risk groups among adults for the influenza, pneumococcal, meningococcal and hepatitis A and B vaccines. The risk groups include pregnant women, patients with HIV infections, cancer patients, patients who have received solid organ and bone marrow transplants, patients with asplenia, health workers, patients with chronic liver, heart and lung disease, diabetes mellitus, and terminally ill patients with chronic kidney disease. The HPV and zoster vaccines are not currently within the scope of the reimbursement [17].

There have been studies into the reasons why vaccinations are not carried out during the adulthood period $[18,19]$. In the study by Johnson et al, $60 \%$ of the adults participating in the study stated that they were "healthy and did not need vaccinations", 58\% stated that their "doctor had not provided any information" and $40 \%$ stated that that they were "afraid of side effects of vaccines." [18]. The most frequent (34.4\%) reason for not getting vaccine in our study was "lack of or insufficient knowledge about vaccines". The other reasons which were stated were "no particular reason but I don't want to get a vaccine" $(27.2 \%)$, "fear of the side effects" $(9.0 \%)$, "the belief that vaccinations do not protect against disease" (8.8\%), "the fact that they are not in the scope of reimbursement" (5.8\%) and "the fact that their costs are high" $(4.7 \%)$. Participants stated that if they had had knowledge on vaccines, they would have get vaccinations. Sixty five percent of participants requested that their family practitioners give them information concerning the required vaccinations.

There are numerous studies which have shown that strategies for the improvement of vaccination rates among adults have been successful [20]. In a study carried out by the National Infectious Diseases Foundation in the USA, patients stated that the recommendation of their physician was important in their decision to get vaccinations. The rate of vaccinations among adults increases where physicians strongly recommend getting vaccination [20-23]. Vaccination coverage during the adulthood period are far from the desired targets in many countries. In a study conducted in the USA, adult vaccination coverage were found to be as follows: influenza $-44.8 \%$; pneumococcal in risk groups under 65 age $-24.65 \%$, and 65 years and over $-63.6 \%$; hepatitis $\mathrm{B}-24.6 \%$; herpes zoster 65 years and over $-34.2 \%$; a minimum of one dose of HPV in females ages 19-26 - 41.6\% and in males - 10.1\% [2]. In Canada, where health services are completely free of charge, adult vaccination coverage are as follows: influenza in adults 18 years and over $-40.3 \%$; tetanus $-49.5 \%$; and pneumococcal vaccination in adults 65 years and over $36.5 \%$ [8]. In a study conducted by $\mathrm{Wu}$ et al, the adult vaccination coverage in European countries were also found to be far from desired targets [3]. In our study, regular vaccination coverage for tetanus were found to be $24.3 \%$, regular vaccination coverage for influenza were found to be $10.8 \%$, vaccination coverage for pneumococcal (for those aged over 65) was $11.1 \%$, hepatitis B was $30.3 \%$, herpes zoster (65 years and over) was $0.2 \%$, and at least one dose of HPV in females aged 19-26 was 2.5\%. This vaccination coverage are too far from the desired targets.

WHO, ACIP, and CDC recommend the influenza vaccine to everyone from the age of 6 months and older, before the influenza season [4,8]. The influenza vaccine was placed within the scope of reimbursement for targeted risk groups in Turkey, in 2004. The vaccination has been offered to all health workers free of charge since 2010. In our study, the seasonal influenza vaccination coverage (in any influenza season) are $39.8 \%$ in aged 18 and older, $26.2 \%$ in the $18-49$ age group, $37.7 \%$ in the 50-64 age group, $55.6 \%$ in the 65 and older, and $45.9 \%$ among health workers. These rates are lower than those present in the USA, and Canada [2,4,8]. However, in certain studies conducted with professional athletes in Turkey, it has been seen that the rate of influenza vaccinations are higher than that of the normal population. In the study carried out by Kavukcu et al, with professional footballers, the rate of regular influenza vaccinations among the participants, on a yearly basis, throughout the whole 5-year term of the study, was $75 \%$ [24]. This group is the equivalent of the 18-49 age group in our study, where the rate of influenza vaccinations was $26.2 \%$. It can be seen from here that the rate of vaccinations among the professional footballers is almost three times the rate we found in our study.

Infants under the age of six months and children are faced with a high risk of death and admittance to hospital in related influenza. The risks of admittance to hospital, premature birth and babies with low birth weight in related influenza, increase in pregnant women. The rates of influenza suffered by infants, whose mothers had influenza vaccinations during pregnancy, are lower [25-27]. The ACIP and the WHO recommend influenza vaccinations during pregnancy [6]. In our study, it was determined that only $16.7 \%$ of pregnant participants had influenza vaccination.

In Turkey and most countries, a booster dose of the tetanus vaccine is recommended routinely every 10 years, The rate of the tetanus toxoid (Td) vaccination among individuals aged 19 and older in the last 10 years is $62.1 \%$ in the USA (according to 2015 data), $49.5 \%$ in Canada (according to 2014 data) and

21 | P a g e 
$71.4 \%$ in Germany (according to 2013 data) $[2,8,11]$. In our study, the rate of regular Td vaccination every 10 years was $24.3 \%$, which is much lower than the data of other countries.

Pertussis is an illness which is characterised by paroxysmal coughing. Infants are under the risk of severe pertussis [27]. The effect of the pertussis vaccine decreases over time, while the antibodies which pass from mother to baby are not able to sufficiently protect the infant in the first 6 months. Therefore, ACIP recommends one dose of Tetanus diphtheria and acellular pertussis vaccine (Tdap) to pregnant women and adults over the age of 19 who have not previously been vaccinated [6]. In Turkey, Tdap is not within the scope of reimbursement in adults and pregnant women, and is not routinely getting. There are no participants who had Tdap vaccinations in our study.

Pneumococcus is an encapsulated bacterium which causes a wide range of infections from otitis to septicaemia. The pneumonia, meningitis and septicaemia caused by pneumococcus is a threat to life, especially in children, in elderly, in people with immune deficiency, and those with splenectomy. Therefore, pneumococcal vaccination is crucial for people in the risk group for pneumococcal diseases $[20,28]$. Pneumococcal vaccination coverage are as follows: the USA (according to 2015 data) $-21.2 \%$ among the 19-64 age group and 59.7\% among the 65 and over age group; Canada (according to 2014 data) $-17.3 \%$ among the 19-64 age group and $36.5 \%$ among the 65 and over age group; Germany (according to 2013 data) $-31.4 \%$ among the 65 and over age group [2,8,11]. In our study, the rates of pneumococcal vaccinations amongst participants were found to be as follows: $20.5 \%$ in the $18-64$ age group and $11.1 \%$ in the 65 and older age group. In our study, the pneumococcal vaccination rates were lower than those in the USA and Canada $[2,4,8]$.

Zona is a considerably painful disease caused by herpes zoster. The Herpes Zoster vaccine (HZV) reduces the frequency with which zoster is seen as well as post-herpetic neuralgia, in individuals aged 60 and older $[20,29,30]$. HZV is not within the scope of reimbursement in Turkey. According to the 2015 data of the USA, the rate of HZV in individuals aged 60 and over is 30.6\% [2]. In our study, the rate of HZV is just $3.2 \%$.

The human papillomavirus (HPV) is responsible for $70 \%$ of cervical cancers among women. It also causes anal, vulvar, vaginal, penile and oropharyngeal cancers and warts in both men and women. It is known that the effect of the HPV vaccine on cervical and anal cancers and genital warts is over $90 \%$ $[20,31,32]$. The HPV vaccine has not included in the national vaccination schedule in Turkey, and it has not within the scope of reimbursement. Therefore, HPV vaccination coverage is extremely low $-0 \%$ in males and 2.5\% in females aged 19-26. This rate is much higher in the USA and Canada, where the HPV vaccine is included in the national vaccination schedule (41.6\% in the USA, $44.7 \%$ in Canada) $[2,8]$.

Health workers are an important target group of adult vaccinations for the purposes of protecting both themselves and their patients they come into contact with. Seventy five percent of health workers receive the seasonal influenza vaccination in the USA [33]. According to the CDC, the highest vaccination coverage in 2014-2015 were among pharmacists, with 95\%. Pharmacists were followed by physicians and nurses, with $89 \%$ [34]. In a study covering 441 health workers in Greece, the rate of those getting the seasonal influenza vaccination was found to be $28.7 \%$ [35]. In our study, the rates of regular seasonal influenza vaccinations among health workers were as follows: pharmacists $-80.0 \%$, emergency medical technicians $-66.7 \%$, midwives $-53.8 \%$ and physicians $-52.0 \%$. These rates of vaccination are lower than those of the USA, but higher than those of Greece.

The WHO and the ACIP recommend that health workers have the hepatitis B vaccination. The rates at which health workers have the hepatitis B vaccination are $64.7 \%$ in the USA, $72.2 \%$ in Canada, $87 \%$ in France and $70.1 \%$ in Italy $[2,8,37]$. In our study, this rate was found to be close to the rate in the USA at $60.4 \%$.

\section{Conclusion}

Vaccinations are the cornerstone of being protected against infectious diseases. Adult vaccinations are a protective health measure, the importance of which continues to increase throughout the world as well as in our country. They reduce the burden of illness and protect life. However, despite targets having been set, adult vaccination targets have not yet been reached, even in developed countries. In our study, the vaccination rates for influenza, pneumococcal, HPV, tetanus, pertussis and zoster are very much below the desired targets. The vast majority of patients cited lack of knowledge as the reason why they were not vaccinated, and wanted family practitioners to inform them concerning the required vaccinations. Family practitioners should assess the vaccination status of the patient in all clinical encounters and strongly recommend the required vaccinations.

The strength of the study is its research into the beliefs which prevent vaccinations and the factors which will increase the rate of vaccinations, alongside the present rate of vaccinations. The weakness of the study is that it is restricted to a certain region and has not been adapted to the whole country.

22 | P a g e 
Declaration of conflicting interests: Autors have no conflict of interest.

The research is registered to the Turkey Higher Education Board (YÖK) with number 433231.

\section{References}

1. National Foundation for Infectious Diseases. Adult Vaccination Saves Lives. 2012. Available at www.adultvaccination.org/resources/cta-adult.pdf. Accessed 4 April 2017.

2. Williams WW, Lu P, O'Halloran A, et al. Surveillance of Vaccination Coverage among Adult Populations - United States, 2015. MMWR Surveill Summ 2017; 66 (No. SS-11): 1-28. DOI: http://dx.doi.org/10.15585/mmwr.ss6611a1.

3. Wu LA, Kanitz E, Crumly J, D'Ancona F, Strikas RA. Adult immunization policies in advanced economies: vaccination recommendations, financing, and vaccination coverage. Int $\mathrm{J}$ Public Health 2013; 58: 865-874.

4. Healthy People 2020. Available at Access: http://www.healthypeople.gov/2020/topicsobjectives/topic/immunization-and-infectious-diseases, Accessed 20 April 2015.

5. Tan L. Adult vaccination: Now is the time to realize an unfulfilled potential. Human Vaccines \& Immunotherapeutics 2015; 11(9): 2158-2166.

6. Kim DK, Riley LE, Harriman KH, Hunter P, Bridges CB, on behalf of the Advisory Committee on Immunization Practices. Recommended Immunization Schedule for Adults Aged 19 Years or Older, United States, 2017. Annals of Internal Medicine, 2017; 166(3): 209-219.

7. Türkiye Enfeksiyon Hastalıkları Ve Klinik Mikrobiyoloji Uzmanlık Derneği (EKMUD) Erişkin Bağışıklama Rehberi Çalışma Grubu Erişkin Bağışıklama Rehberi 2016.

8. Vaccine uptake in Canadian adults: results from the 2014 adult National Immunization Coverage Survey 2014. Available at https://www.canada.ca/en/publichealth/services/publications/healthy-living/vaccine-uptake-canadian-adults-results-2014-adultnational-immunization-coverage-survey.html Accessed 4 April 2015.

9. Kanitz EE, Wu LA, Giambi C, Strikas RA, Levy-Bruhl D et al. VENICE (vaccine european new integrated collaboration effort) national gatekeepers, contact points. Variation in adult vaccination policies across Europe: an overview from VENICE network on vaccine recommendations, funding and coverage. Vaccine 2012; 30: 5222-8; PMID:22721901; http://dx.doi.org/10.1016/j.vaccine.2012.06.012

10. Dyda A, Karki S, Hayen A, MacIntyre CR, et al. Influenza and pneumococcal vaccination in Australian adults: a systematic review of coverage and factors associated with uptake. BMC Infectious Diseases, 2016; 16: 515.

11. Poethko-Müller C, Schmitz R. Vaccination coverage in German adults. Results of the German Health Interview and Examination Survey for Adults (DEGS1). Bundesgesundheitsblatt Gesundheitsforschung - Gesundheitsschutz. 2013; 5(6); 201-210

12. Turhan Ö, Polat HH, Öncel S, Akcan A, et al. Pneumococcal Vaccination Status in Adults SixtyFive Years and Older, Kuwait Medical Journal 2010; 42(2): 135-138.

13. Zeybek Y, Tokalak İ, Boyacıoğlu S. Altmış beş yaş ve üzeri erişkinlerde aşılanma Durumu. Türk Geriatri Dergisi 2004; 7 (3): 152-154.

14. Aşık Z, Çakmak T, Bilgili P. Erişkinlerin erişkinlik dönemi aşıları hakkındaki bilgi, tutum ve davranışları, Türk Aile Hek. Derg. 2013; 17(3): 113-118 
15. Balbay G, Tanrıverdi E, Alaşan F, Süner KÖ. Düzce ilinde kronik obstruktif akciğer hastalığ tanılı hastaların aşılanma sıklığı. Düzce Üniversitesi Sağlık Bilimleri Üniversitesi Dergisi, 2013; 3(2): $15-17$

16. Biberoğlu K, Biberoğlu S, Özbakkaloğlu M, Bilgir O et al. Haydi Büyükler Aşıya, TIHUD Ege Çalışma Grubu, available http://www.tihud.org.tr/main/content?ref=2\&child=179 Accessed 5 May 2015

17. T.C.Sağlık Bakanlığı, Türkiye Halk Sağlığı Kurumu, Aile Hekimliği Uygulamasında Önerilen Periyodik Sağlık Muayeneleri ve Tarama Testleri, 2015; ss 60-62

18. Johnson DR, Nichol KL, Lipczynski K. Barriers to Adult Immunization, Am J Med 2008; 121 : S28-S35.

19. Centers for Disease Control and Prevention (CDC). Intent to receive influenza A (H1N1) 2009 monovalent and seasonal influenza vaccines-two countries, North Carolina, 2009. MMWR Morb Mortal Wkly Rep 2009; 58: 1401-1410.

20. Bridges CB, Hurley LP, Williams WW, Ramakrishnan A, Dean AK, GroomAV. Meeting the Challenges of Immunizing Adults. Am J Prev Med 2015; 49(6S4): 455-464,

21. Ünal S, Durusu Tanrïver M, Taş E, Güner İ, Çetin ÖY, Sayar İ. Pneumococcal vaccination coverage in the elderly population: before and after setting a target with a one-day educational program. Flora 2014; 19:2-7.

22. The Adult Vaccine Access Coalition (AWAC). Financial Barriers to Adult Immunization. Available https://www.adultvaccinesnow.org/about/ Accessed 5 May 2015

23. Lu P-J, O'Halloran A, Williams WW. Impact of Health Insurance Status on Vaccination Coverage Among Adult Populations. Am J Prev Med 2015; 48(6): 647-661

24. Kavukcu E, Burgazlı KM. Preventive Health Perspective in Sports Medicine: The Trend at the Use of Medications and Nutritional Supplements during 5 Years Period between 2003 and 2008 in Football. Balkan Med J. 2013; 30(1): 74-9.

25. MacDonald NE, McDonald JC. Canadian Paediatric Society Infectious Diseases and Immunization Committee, The benefits of influenza vaccine in pregnancy for the fetus and the infant younger than six months of age. Paediatr Child Health 2014; 19(9): e121-122

26. Benowitz I, Esposito DB, Gracey KD, Shapiro ED, Va'zquez M. Influenza Vaccine Given to Pregnant Women Reduces Hospitalization Due to Influenza in Their Infants. Clinical Infectious Diseases 2010; 51(12): 1355-1361

27. Forsyth K, Plotkin S, Tan T, Von Konig CHW, Strategies to decrease Pertussis Transmission to infants. Pediatrics 2015;135(6);e1475-e1482

28. Centers for Disease Control and Prevention. Pneumococcal Disease, Epidemiology and Prevention of Vaccine-Preventable Diseases, 13 ${ }^{\text {th }}$ Edition, 2015, available http://www.cdc.gov/vaccines/pubs/pinkbook/downloads/pneumo.pdf, Accessed 5 May 2015

29. Oxman MN, Levin MJ, Johnson GR, et al. A vaccine to prevent herpes zoster and postherpetic neuralgia in older adults. N Engl J Med 2005; 352: 2271-2284. DOI: 10.1056/NEJMoa051016

30. Lal H, Cunningham AL, Godeaux O, Chlibek R et al. Efficiacy of an adjuvanted Herpes Zoster Subunit vaccine in older adults. N Engl J Med. 2015; 372(22): 2087-2096. 
31. Markowitz LE, Dunne EF, Saraiya $M$, et al. Human papillomavirus vaccination: recommendations of the Advisory Committee on Immunization Practices (ACIP). MMWR Recomm Rep 2014; 63(No.RR-05): 1-30.

32. de Sanjosé S, Alemany L, Ordi J, et al. Worldwide human papillomavirus genotype attribution in over 2000 cases of intraepithelial and invasive lesions of the vulva. Eur J Cancer 2013; 49: 3450-3461.

33. Influenza Vaccination Coverage Among Health Care Personnel - United States, 2013-14 Influenza Season Weekly, 2014; 63(37); 805-811

34. Influenza Vaccination Coverage Among Health Care Personnel - United States, 2014-15 Influenza Season Weekly, 2015; 64(36); 993-999.

35. Rachiotis G, Mouchtouri VA, Kremastinou J, Gourgoulianis K, Hadjichristodoulou C. Low acceptance vaccination against the 2009 pandemic influenza $\mathrm{A}(\mathrm{H} 1 \mathrm{~N} 1)$ among healthcare workers in Greece. Euro Surveill 2010; 15(6): pii= 19486.

36. Forsyth K, Plotkin S, Tan T, Von Konig CHW, Strategies to decrease Pertussis Transmission to infants. Paediatrics 2015; 135(6); e1475-e1482.

37. Haviari S, Benet T, Saadathan-Elahi M, Loulergue P, Vanhems P. Vaccination of healthcare workers: A review. Human Vaccines \& Immunotherapeutics, 2015; 11(11): 2522-2537. 